\title{
Efeito do cozimento na qualidade do músculo Semitendinosus
}

\author{
Effect of cooking on the quality of beef Semitendinosus muscle
}

\section{Marielen de Lima SILVA ${ }^{1}$, Carmen Josefina CONTRERAS-CASTILLO ${ }^{*}$, Edwin Moisés Marcos ORTEGA ${ }^{3}$}

\section{Resumo}

O presente experimento foi realizado para determinar a efetividade do tratamento térmico em água e vapor a $80{ }^{\circ} \mathrm{C}$ tendo como objetivo a inativação do Clostridium botulinum tipo E, utilizando-se amostras de Semintendinosus. Foram realizadas ainda a avaliação da maciez objetiva, utilizando-se a análise de força de cisalhamento, e a avaliação sensorial dos atributos de suculência, maciez subjetiva, "flavor" e presença de colágeno. $\mathrm{O}$ tratamento a $80^{\circ} \mathrm{C}$ foi efetivo na eliminação do microrganismo, contudo não houve diferença significativa no atributo maciez objetiva (força de cisalhamento) avaliado nos dois tratamentos utilizados. A avaliação sensorial apresentou correlação positiva entre os atributos maciez e suculência, enquanto o colágeno apresentou correlação negativa com a maciez. O "flavor" não apresentou correlação com os atributos maciez, suculência e presença de colágeno.

Palavras-chave: Clostridium botulinum tipo E; termobacteriologia; carne; maciez; qualidade; cozimento.

\begin{abstract}
The purpose of the experiment reported here was to determine the effectiveness of heat treatments in water and in steam at $80{ }^{\circ} \mathrm{C}$ to inactivate the bacterium Clostridium botulinum type $\mathrm{E}$ in samples of beef Semitendinosus muscle. The product's tenderness was evaluated based on a Warner-Bratzler Shear Force (WBSF) analysis and its attributes of juiciness, subjective tenderness, flavor and connective tissue were evaluated sensorially. The treatment at $80{ }^{\circ} \mathrm{C}$ effectively killed the bacterium, but no significant difference was found in the attribute of objective tenderness (shear force) evaluated after the two treatments. The sensorial analysis indicated a positive correlation between the attributes of juiciness and tenderness, while the connective tissue showed a negative correlation to tenderness. Flavor proved uncorrelated with tenderness, juiciness and connective tissue.
\end{abstract}

Keywords: Clostridium botulinum type E; thermobacteriology; beef; tenderness; quality; cooking.

\section{Introdução}

Os hábitos e preferências do consumidor aliados ao estilo de vida moderno têm mostrado uma forte tendência ao consumo de alimentos prontos congelados. Os produtos prontos para consumo embalados e tratados termicamente são muito apreciados pelos consumidores. As características de qualidade realçadas, além de vida de prateleira mais longa, são os principais fatores que levam à compra dos referidos produtos ${ }^{13}$.

A segurança alimentar constitui-se também num fator importante a ser considerado no tratamento de produtos elaborados industrialmente. A respeito do processamento industrial, VAUDAGNA et al. ${ }^{22}$ destacaram dois riscos à saúde pública que este tipo de produção pode introduzir. O primeiro inclui os microrganismos produtores de toxina termo estável como S. aureus e Bacilus cereus. Neste caso, a segurança do alimento depende crucialmente da existência ou não de toxinas na matéria-prima. O segundo risco refere-se aos microrganismos psicrotróficos e anaeróbios facultativos como a Listeria monocytogenes, Yersinia enterocolitica, Aeromonas hidrophila e patógenos formadores de esporos como o Clostridium botulinum tipo $\mathrm{E}$.

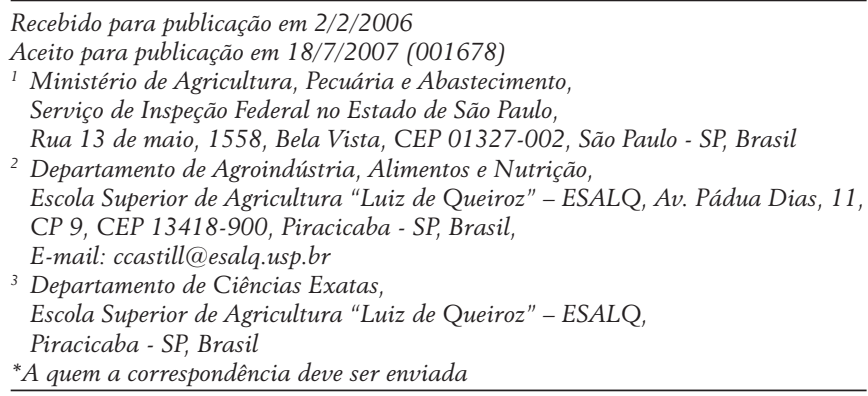

O efeito do cozimento nas proteínas miofibrilares foi estudado por vários autores citados na revisão realizada por TORNBERG ${ }^{21}$. Nesta publicação, indica-se que uma curva típica de aquecimento de um músculo está constituída por três zonas de transição. A primeira ocorre com temperaturas entre $54 \mathrm{e}$ $58{ }^{\circ} \mathrm{C}$ e atribui-se às alterações na miosina, a segunda ocorre entre $65-67^{\circ} \mathrm{C}$ e refere-se às mudanças no colágeno e nas proteínas sarcoplasmáticas, enquanto que a terceira designa-se a actina quando aquecida entre $80-83^{\circ} \mathrm{C}$.

Dentre as características sensoriais, a maciez, suculência e o "flavor" são as mais exigidas pelo consumidor, sendo a maciez a mais passível de modificação via controle de processo, daí a importância das práticas de gerenciamento e controle de processo de modo a incrementar a qualidade sensorial dos produtos prontos para consumo ${ }^{20}$. A maciez não varia somente entre as carcaças, mas também entre os músculos e ainda dentro de um mesmo músculo. Existem muitos fatores que podem influenciar na diferença da maciez entre os músculos. A fibra muscular e o tecido conectivo contribuem com a maciez final em cada um dos fatores. Existe uma dificuldade extrema em diferenciar e medir as contribuições de cada um deles na maciez muscular O tecido conectivo intramuscular é um constituinte importante quando as propriedades físicas da carne são consideradas, embora a quantidade de colágeno e elastina presentes nos músculos sejam baixas ${ }^{10}$.

O cozimento induz a mudanças estruturais e diminui a capacidade de retenção de água da carne (CRA) que está ligada à suculência ${ }^{21}$. Segundo $\mathrm{OFFER}^{8}$, à temperatura de 60 a $70{ }^{\circ} \mathrm{C}$ a rede do tecido conectivo e fibras musculares conjuntamente encolhem de modo longitudinal, e a extensão deste encolhimento aumenta com a temperatura. Em conseqüência, tem-se uma 
grande perda de água que é obtida no cozimento. Presume-se que a água é expelida pela pressão exercida por este encolhimento no tecido conectivo, exercendo influência na percepção sensorial de suculência nas amostras de carne.

Os objetivos do trabalho foram avaliar a efetividade do tratamento térmico aplicado às amostras sob o ponto de vista microbiológico, tendo como microrganismo alvo o Clostridium botulinum tipo E e a maciez objetiva (força de cisalhamento). A avaliação sensorial foi realizada aferindo em que medida a maciez exerceu influência nos atributos "flavor", presença de colágeno e suculência das amostras submetidas ao cozimento em temperaturas de $80^{\circ} \mathrm{C}$ utilizando água e vapor.

\section{Material e métodos}

A matéria-prima foi constituída de cortes, músculo Semitendinosus, não maturados, de animais da raça Nelore abatidos com idade aproximada de 3,5 anos.

As peças foram embaladas a vácuo, em embalagem marca Cryovac CN-614. Trata-se de embalagem termoencolhível constituída por sacos do tipo "cook in", com estrutura multicamadas, constituída de copolímeros poliolefínicos, nylon e EVOH, sendo a camada externa de polietileno de alta densidade. A embalagem, de alta barreira ao vapor d'agua, possui permeabilidade máxima ao oxigênio de $25 \mathrm{~cm}^{3}$ (CNTP) $/ \mathrm{m}^{2} / \mathrm{dia}$ a $1 \mathrm{~atm}, 25^{\circ} \mathrm{C}$ e $75 \%$ UR.

O cozimento foi realizado utilizando-se vapor e água. O cozimento a vapor foi feito em estufa com circulação de vapor, marca Becker, modelo RKB1 e capacidade para $2300 \mathrm{~L}$ por ciclo. Para o cozimento em água foram utilizados tachos de aquecimento com capacidade de $100 \mathrm{~L}$ de aço inox de dupla camisa. O objetivo foi atingir a temperatura de $80{ }^{\circ} \mathrm{C}$ no ponto frio da amostra. As temperaturas encontradas foram registradas a cada 2 minutos. Uma vez atingida a temperatura desejada, as amostras foram retiradas do meio de cozimento, resfriadas e armazenadas. As amostras, após o processamento, foram armazenadas na câmara fria durante 24 horas em temperatura de $0{ }^{\circ} \mathrm{C}$, até o momento da realização das análises ${ }^{22}$.

\subsection{Avaliação do processo de cozimento}

A letalidade total, tendo como microrganismo de referência o Clostridium botulinum tipo E, obtida nos processamentos em cada tratamento foi calculada através da utilização do método genérico, para o qual foi construída uma curva de penetração de calor nas amostras, utilizando-se a fórmula $10^{(\mathrm{X}-\mathrm{Y}) / \mathrm{Z}}$, onde $\mathrm{X}$ foi a temperatura no ponto frio da amostra em cada intervalo medido ( 2 minutos), Y foi a temperatura de referência $\left(80^{\circ} \mathrm{C}\right)$ e $\mathrm{Z}$ foi a taxa letal do microrganismo $\left(8,8^{\circ} \mathrm{C}\right)$. A letalidade foi calculada em cada intervalo de tempo analisado, sendo, em seguida, realizada a somatória das letalidades a cada intervalo, encontrando-se a letalidade total.

Para o cálculo do valor de pasteurização (P), utilizou-se o somatório das contribuições letais (letalidade total) de cada estágio de temperatura multiplicada pelo intervalo de tempo em que cada temperatura foi medida ( 2 minutos).
O número de reduções decimais, obtido durante o processamento, foi calculado através da divisão do valor encontrado (P) dividido pelo valor ajustado (D) para a temperatura de $80^{\circ} \mathrm{C}$ em cada um dos tratamentos. Como os valores padrão para o microrganismo de escolha foram calculados com base em uma temperatura teste de $82,2{ }^{\circ} \mathrm{C}$, foi necessário fazer um reajuste para a realização dos cálculos da temperatura utilizada no experimento $\left(80^{\circ} \mathrm{C}\right)$. Este cálculo foi realizado utilizando-se a fórmula $\mathrm{D} 1 / \mathrm{D} 2=10^{(\mathrm{T} 2 \mathrm{~T} 1) / 2}$, onde:

$\mathrm{D}_{82,2}=0,1-3,0$ e $\mathrm{Z}=5,0-8,8$

$\mathrm{D}_{80}=5,33$ para temperatura de $80{ }^{\circ} \mathrm{C}$

\subsection{Maciez objetiva - medida da força de cisalhamento}

Para a realização da medição física de um músculo, foram retirados bifes com $2,5 \mathrm{~cm}$ de espessura no sentido transversal às fibras musculares das porções inicial, mediana e caudal. De cada bife foram retiradas 10 amostras cilíndricas com diâmetro de 1,27 cm de seção transversal, cortadas paralelamente à fibra muscular. A determinação da maciez objetiva foi feita submetendo-se cada amostra ao teste da força de cisalhamento, utilizando-se o texturômetro TA-XT 2i acoplado à lâmina Warner Braztler. O equipamento foi calibrado com peso padrão de $5 \mathrm{~kg}$ rastreável. A velocidade de descida do dispositivo foi de $200 \mathrm{~mm} / \mathrm{min}$, seguindo as recomendações da $\mathrm{AMSA}^{1}$.

\subsection{Avaliação sensorial}

A análise sensorial foi realizada utilizando-se teste quantitativo para maciez, suculência, presença de colágeno e "flavor". Este experimento foi conduzido no Laboratório de Análise Sensorial do ITAL-Centro de Tecnologia de Carnes, com uma equipe de sete a treze provadores treinados, mostrando bom poder discriminativo $\left(\mathrm{p}_{\mathrm{F} \text { amostra }}<0,30\right)$, boa reprodutibilidade nos julgamentos $\left(\mathrm{p}_{\mathrm{F} \text { repeticóes }}>0,05\right)$ e consenso com os demais membros da equipe. Trata-se de uma equipe treinada do próprio CTC. Na avaliação da intensidade de cada atributo nas amostras, foi utilizada escala estruturada de $10 \mathrm{~cm}$, sendo considerado o número 0 da escala como pouco macia, 5 como macia e 10 como muito macia. Na avaliação da suculência, 0 foi estabelecido como amostra pouco suculenta, 5 como suculenta e 10 como muito suculenta. A quantidade de tecido conectivo (colágeno) foi de 0 como nenhuma, 5 moderada e 10 abundante. Enquanto intensidade do sabor foi de 0 como pouco, 5 moderado e 10 intenso. Foram apresentadas duas amostras de cada tratamento, perfazendo um total de quatro amostras, todas codificadas com números de três dígitos escolhidos de forma aleatória. Os dados foram coletados em sistema informatizado da Compusense Inc., Canadá, versão 4.2.

\subsection{Delineamento experimental}

Os métodos de cozimento em água e em vapor foram testados para uma temperatura de $80^{\circ} \mathrm{C}$, em duas replicações, sendo que em cada replicação foram realizadas duas repetições. 


\subsection{Análises estatísticas}

No primeiro estágio do experimento, teve-se um fator tipo de cozimento com 2 níveis (água e vapor), utilizou-se o teste de hipóteses T-student para avaliar a maciez objetiva em relação ao fator, utilizando um nível de 5\% de significância.

Para avaliação sensorial, foi empregado o teste de correlação de Pearson com nível de significância de 1\%, para conhecer a relação linear entre os atributos maciez, suculência, presença de colágeno e "flavor". Em seguida foram aplicadas análises de Regressão Linear Múltipla, com nível de significância de 5\%.

Para verificar em que medida os atributos presença de colágeno, "flavor" e suculência influenciaram na maciez, foi elaborado um modelo de regressão linear múltipla para saber quais variáveis têm influência positiva ou negativa na maciez das amostras. $O$ modelo empregado foi: $Y_{1}=\beta_{0}+\beta_{1} X_{i 1}+\beta_{2}$ $\mathrm{X}_{\mathrm{i} 2}+\beta_{3} \mathrm{X}_{\mathrm{i} 3}+\mathrm{E}_{\mathrm{i}}$, onde $\mathrm{Y}_{\mathrm{i}}$ é maciez, $\mathrm{X}_{\mathrm{i} 1}$ é suculência, $\mathrm{X}_{\mathrm{i} 2}$ colágeno, $\mathrm{X}_{\mathrm{i} 3}$ "flavor" e $\mathrm{E}_{\mathrm{i}}$ é o erro aleatório. Para as análises estatísticas foi empregado o programa SPSS ${ }^{18}$.

\section{Resultados e discussão}

\subsection{Avaliação do processo de cozimento}

Os tratamentos térmicos aplicados a uma mesma temperatura $\left(80^{\circ} \mathrm{C}\right)$, tanto em água quanto em vapor, não apresentaram diferenças significativas entre os tempos de cozimento (Tabela 1).

Com relação à efetividade do processo de pasteurização no tratamento com temperatura de $80^{\circ} \mathrm{C}$, tanto em água quanto em vapor, observou-se que as reduções decimais alcançadas foram consideradas compatíveis com o desejado para um processo de pasteurização (Tabela 1). Este resultado foi considerado satisfatório e se apresenta em conformidade com as investigações de $\mathrm{STUMBO}^{19}$, que considera bem sucedido o processo de pasteurização no qual ocorra uma redução decimal bacteriana entre 5 (cinco) e 10 (dez) ciclos logarítmicos.

RYBKA et al. ${ }^{15}$, avaliando as características de armazenamento de 14 produtos comerciais cozidos, dentre eles o "roast beef" em embalagens do tipo "cook in", encontraram uma redução de 12D para esporos de C. botulinum não proteolítico utilizando temperatura de $80^{\circ} \mathrm{C}$ durante 255 minutos e mantendo baixas temperaturas de armazenamento. Este resultado foi considerado pelos autores como sendo satisfatório e concorda com os resultados encontrados neste trabalho.

Tabela 1. Tempo total de cozimento e número de reduções decimais alcançadas em cada um dos tratamentos.

\begin{tabular}{|c|c|c|c|c|c|c|c|}
\hline \multirow[t]{3}{*}{ Tratamento } & \multirow[t]{3}{*}{$\mathrm{n}^{* *}$} & \multicolumn{3}{|c|}{$\begin{array}{c}\text { Tempo total de } \\
\text { cozimento (minutos) }\end{array}$} & \multicolumn{3}{|c|}{$\begin{array}{l}\mathrm{N}^{\circ} \text { de reduções decimais } \\
\text { alcançadas (valor } \mathrm{D} \text { ) }\end{array}$} \\
\hline & & \multicolumn{2}{|c|}{ Processamento* } & \multirow[t]{2}{*}{ Média } & \multicolumn{2}{|c|}{ Processamento* } & \multirow[t]{2}{*}{ Média } \\
\hline & & 1 & 2 & & 1 & 2 & \\
\hline Água $80^{\circ} \mathrm{C}$ & 6 & 106 & 100 & $103^{a}$ & 10,3 & 12,2 & $11,3^{\mathrm{b}}$ \\
\hline Vapor $80^{\circ} \mathrm{C}$ & 6 & 100 & 114 & $107^{\mathrm{a}}$ & 8,3 & 11,9 & $10,1^{\mathrm{b}}$ \\
\hline
\end{tabular}

\subsection{Maciez objetiva}

Os resultados relativos às médias dos índices de maciez objetiva medidas através da força de cisalhamento encontrados no presente trabalho estão descritos na Tabela 2. As forças mecânicas que atuam na carne podem incluir forças de corte, compressão e tensão, as quais podem ser definidas no teste mecânico que foi utilizado nesta pesquisa. $\mathrm{O}$ índice de maciez mais baixo encontrado foi de $5,83 \mathrm{~kg}$. Este valor obtido foi similar ao encontrado por outros pesquisadore ${ }^{12}$ utilizando a mesma temperatura e tipo de cozimento. O músculo Semitendinosus é classificado como um músculo de maciez intermediária ${ }^{16}$, justificando a resposta quanto ao resultado instrumental e sensorial do Semitendinosus com os dois tipos de cozimento com relação à maciez nesta pesquisa, quando comparado com outros músculos de maciez intermediária como Triceps brachi e Semimembranosus, estudados por PLANT et al. ${ }^{12}$.

O experimento realizado ${ }^{17}$, empregando 10 diferentes cortes de carne bovina cozidas, dentre eles o Semitendinosus, analisou a relação existente entre a maciez objetiva medida pela força de cisalhamento em um aparelho texturômetro equipado com o dispositivo Warner Bratzler (WB) e a maciez subjetiva medida através de avaliação sensorial utilizando um grupo de provadores treinados. As amostras de Semitendinosus foram assadas, e o índice para WBSF encontrado foi de 4,1 kg, uma maciez considerada intermediária pelo autor. A diferença entre os resultados encontrados neste trabalho e os do realizado por aqueles autores pode ser devido à utilização de diferentes métodos de cozimento, bem como ao tempo de maturação de 14 dias utilizado no experimento citado, já que nesta pesquisa não foram utilizados cortes maturados.

Segundo PALKA ${ }^{11}$, no corte de Semitendinosus a desintegração da estrutura miofibrilar começa a $70^{\circ} \mathrm{C}$ e atinge níveis consideráveis a $90^{\circ} \mathrm{C}$. Desta forma, prevê-se então que a $80^{\circ} \mathrm{C}$, temperatura utilizada no experimento, ocorreu uma desintegração intermediária. Assim também argumentou este autor que altas temperaturas não mudam o diâmetro da fibra.

Durante o cozimento da carne alcançando temperatura interna de $80{ }^{\circ} \mathrm{C}$, ocorrem mudanças significativas nas proteínas miofibrilares e no tecido conectivo intramuscular. A presença de colágeno (tecido conectivo) no Semitendinosus foi avaliada sensorialmente nesta pesquisa. PALKA ${ }^{11}$, ao realizar experimento com carne assada à temperatura interna de $80^{\circ} \mathrm{C}$, observou que, como conseqüência deste aquecimento, ocorre a granulação do perimísio e a quebra dos tubos do endomísio. Em decorrência desta temperatura, ocorre provavelmente a influência nos valores de força de cisalhamento, sendo consideradas as amostras dos dois tratamentos no umbral de carne macia e dura, de acordo com valor de $6,0 \mathrm{~kg}^{23}$, na condição de

Tabela 2. Maciez objetiva encontrada em cada tratamento.

\begin{tabular}{ccccc}
\hline $\begin{array}{c}\text { Tipo de } \\
\text { cozimento }\end{array}$ & $\mathrm{n}^{*}$ & $\begin{array}{c}\text { Temperatura de } \\
\text { cozimento }\left({ }^{\circ} \mathrm{C}\right)\end{array}$ & $\begin{array}{c}\text { Maciez objetiva } \\
(\mathrm{kg})\end{array}$ & Erro padrão \\
\hline Água & 40 & $80^{\circ} \mathrm{C}$ & 5,8 & 0,4 \\
Vapor & 40 & $80^{\circ} \mathrm{C}$ & 6,5 & 0,4 \\
\hline $\mathrm{n}=$ número de amostras. & & &
\end{tabular}


limite máximo para carnes de maciez aceitável, enquanto que

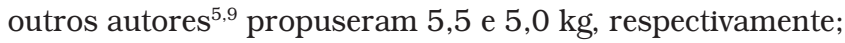

Os valores de forças de cisalhamento resultantes de pesquisas realizadas em diversas instituições quanto aos limites de maciez devem ser utilizados com precaução, devido não somente aos resultados terem sido obtidos por diferentes laboratórios, como também pelos métodos de padronização que podem variar consideravelmente ${ }^{23}$. Devem-se considerar também diferenças culturais e regionais para a percepção e definição dos limites de uma carne macia ${ }^{4,7}$.

Pelos dados da Tabela 3, a qual apresenta o teste de diferenças de médias referentes aos tratamentos avaliados, verifica-se que não foram constatadas diferenças significativas $(p>0,05)$ entre os métodos de cozimento utilizados.

Tabela 3. Diferença de média entre os tratamentos.

\begin{tabular}{lcccccc}
\hline \multicolumn{6}{c}{ Teste de diferenças de médias } \\
\hline & $\mathrm{n}^{* *}$ & $\mathrm{~T}$ & g.l. & $\begin{array}{c}\text { Sig } \\
(2 \mathrm{~T})^{*}\end{array}$ & $\begin{array}{c}\text { Dif. } \\
\text { médias }\end{array}$ & $\begin{array}{c}\text { Erro padrão } \\
\text { das diferenças }\end{array}$ \\
\hline $\begin{array}{l}\text { Variâncias } \\
\text { diferentes }\end{array}$ & 40 & $-1,326$ & 77 & 0,189 & $-0,7550$ & 0,5692 \\
*Significância ao nível de 5\%; ${ }^{* *} \mathrm{n}=$ número de amostras.
\end{tabular}

Segundo TORNBERG ${ }^{21}$ e ROWE ${ }^{14}$, durante o cozimento, as diferentes proteínas desnaturam e podem causar mudanças estruturais tais como a destruição das membranas celulares, encolhimento transversal e longitudinal das fibras da carne, agregação e formação de gel de proteínas sarcoplasmáticas e o encolhimento e a solubilização do tecido conectivo. O encolhimento das fibras musculares inicia-se a $60{ }^{\circ} \mathrm{C}$. Ao atingir temperaturas em torno de $65{ }^{\circ} \mathrm{C}$ inicia-se a agregação e formação de gel, responsável por aumento na maciez do produto. Do equilíbrio entre estes dois fatores, resultará uma maior ou menor maciez da carne, que devem ser considerados pela temperatura de cozimento utilizada neste experimento $\left(80^{\circ} \mathrm{C}\right)$. Por um outro lado, CALIFANO et al. ${ }^{2}$ argumentaram que, à medida que houve um incremento da temperatura para $65^{\circ} \mathrm{C} \mathrm{e} 75^{\circ} \mathrm{C}$, a textura do músculo Semitendinosus mostrou-se mais dura.

\subsection{Avaliação sensorial}

A avaliação sensorial foi realizada verificando-se os atributos maciez, suculência, colágeno e "flavor" para os tipos de cozimentos em água e em vapor, na temperatura de $80^{\circ} \mathrm{C}$. Durante a mastigação da carne acontece a deformação e fratura das amostras. Pelos resultados obtidos na maciez, pode considerar-se carne macia pela escala utilizada onde o valor de 5 representou como macia (Tabela 4). Autores como TORNBERG ${ }^{21}$ realizaram experimentos com carne inteira do músculo Bíceps femoris e observaram que o endurecimento diminui drasticamente de 55 a $60{ }^{\circ} \mathrm{C}$, aumentando posteriormente quando a temperatura atinge $80{ }^{\circ} \mathrm{C}$, como utilizado neste experimento. Esses valores estariam em contraposição com os resultados encontrados no presente experimento, supostamente devido aos métodos de cozimento aqui utilizados (cozimento com água e vapor).
Pelos resultados obtidos, observa-se que não foram encontradas diferenças significativas entre os dois tratamentos térmicos, para nenhum dos atributos sensoriais avaliados (Tabela 4).

Tabela 4. Média das notas resultantes da avaliação sensorial.

\begin{tabular}{lcccc}
\hline Tratamento & Maciez & Suculência & Colágeno & "Flavor" \\
\hline Água $80^{\circ} \mathrm{C}$ & $5,91^{\mathrm{a}}$ & $4,63^{\mathrm{b}}$ & $1,75^{\mathrm{c}}$ & $5,05^{\mathrm{d}}$ \\
Vapor $80^{\circ} \mathrm{C}$ & $5,47^{\mathrm{a}}$ & $4,51^{\mathrm{b}}$ & $2,63^{\mathrm{c}}$ & $5,41^{\mathrm{d}}$ \\
\hline
\end{tabular}

Nota: os resultados correspondem à avaliação realizada utilizando-se uma escala não estruturada, sendo os números 0 e 10 correspondentes aos extremos da escala de intensidade para os atributos maciez, suculência, presença de colágeno e "flavor".

Para saber a relação existente entre os atributos maciez, suculência, colágeno e "flavor", inicialmente foi realizada a análise de correlação de Pearson. Pelos resultados encontrados para o cozimento em água, existe uma correlação significativa em nível de 99\% de confiança entre os atributos maciez e suculência (Tabela 5).

Tabela 5. Correlação entre os atributos de cozimento.

\begin{tabular}{lcccc}
\hline & \multicolumn{4}{c}{ Cozimento em água } \\
\cline { 2 - 5 } & Maciez & Suculência & Colágeno & "Flavor" \\
\hline Maciez água & 1 & $0,481^{*}$ & $-0,182$ & 0,058 \\
Suculência & $0,481^{*}$ & 1 & $-0,125$ & 0,088 \\
Colágeno & $-0,182$ & $-0,125$ & 1 & 0,027 \\
"Flavor" & 0,058 & 0,088 & 0,027 & 1 \\
\hline & \multicolumn{5}{c}{ Cozimento em vapor } \\
\cline { 2 - 5 } & Maciez & Suculência & Colágeno & "Flavor" \\
\hline Maciez & 1 & $0,518 *$ & $-0,299 *$ & 0,029 \\
Suculência & $0,518 *$ & 1 & $-0,091$ & $-0,014$ \\
Colágeno & $-0,299 *$ & $-0,091$ & 1 & 0,051 \\
"Flavor" & 0,029 & $-0,014$ & 0,051 & 1 \\
\hline
\end{tabular}

${ }^{*}$ Existe significância em nível de $1 \%$.

Pelos resultados obtidos para o cozimento em vapor, verificou-se que existe uma correlação significativa em nível de $1 \%(\mathrm{p}<0,01)$, entre as características sensoriais de maciez e suculência e uma correlação negativa entre os atributos presença de colágeno e maciez.

Os modelos estimados da regressão linear múltipla, objetivando avaliar em que medida os atributos presença de colágeno, "flavor" e suculência influenciaram de maneira positiva ou negativa na maciez, para a avaliação sensorial dos tratamentos foram os seguintes:

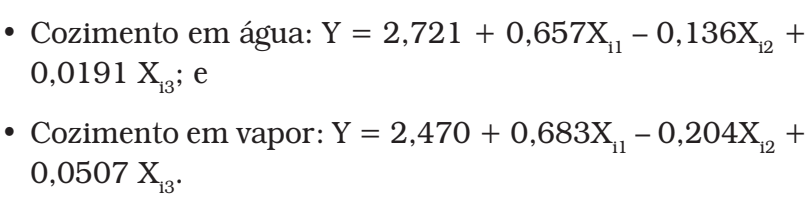

Ao avaliar os resultados obtidos acima, conclui-se que na utilização do cozimento em água, a variável significativa para o modelo foi a suculência $(\mathrm{p}<0,01)$. Isto significa que pequenas mudanças na suculência influenciaram positivamente a maciez com um nível de confiança de 99\%.

Para o tratamento feito com cozimento em vapor, o atributo maciez foi influenciado pela suculência. Porém o colágeno apre- 
sentou uma correlação negativa com a maciez, de modo que um pequeno aumento na quantidade de colágeno implicaria na diminuição da maciez das amostras. Em todos esses resultados foi considerado um nível de significância de $1 \%$.

Em temperaturas de cozimento de 70 a $90{ }^{\circ} \mathrm{C}$ ocorre um aumento do espaço extracelular que pode influenciar tanto na suculência como na maciez das amostras. Porém, de acordo com TORNBERG ${ }^{21}$, o que influencia na suculência da carne cozida é a ocorrência de um preenchimento do perimísio por água do meio a essas temperaturas de cozimento. Neste experimento, o atributo "flavor" não exerceu influência significativa sobre a maciez, para nenhum dos tratamentos térmicos.

COMBES et al. $^{3}$, avaliando a relação tempo-temperatura de cozimento na carne de coelho, demonstram que a maciez objetiva é dramaticamente afetada pela relação tempo-temperatura de cozimento. Além disso, o trabalho estabelece uma comparação na quantidade e solubilidade de colágeno existente na carne de coelho e na bovina e concluem que é a solubilidade do conteúdo colagênico que difere entre as espécies e não a quantidade existente no músculo.

\section{Conclusões}

Os tratamentos térmicos empregados, cozimento em água e em vapor foram eficazes uma vez que a menor redução decimal alcançada foi de 8,33 ciclos logarítmicos no aquecimento com vapor, o que caracteriza um processamento térmico adequado para o Semitendinosus sob o ponto de vista de inocuidade do produto com relação ao microrganismo Clostridium botulinum tipo E. A maciez medida através da avaliação da força de cisalhamento não foi afetada pelo tipo de cozimento e nem mesmo pela temperatura. Na avaliação sensorial, a suculência apresentou uma correlação positiva com a maciez, enquanto que, o colágeno apresentou uma correlação negativa com relação a este atributo.

\section{Referências bibliográficas}

1. AMERICAN MEAT SCIENCE ASSOCIATION AND NATIONAL LIVE STOCK AND MEAT BOARD (AMSA). Research guidelines for cookery, sensory valuation and instrumental tenderness measurements of fresh meat. Chicago, USA, 1995. Cap. 1, p. 7-33.

2. CALIFANO, A. N. et al. Effect of processing conditions on the hardness of cooked beef. Journal Food Engineering, v. 34, n. 1, 1997.

3. COMBES, S. et al. Effect of cooking temperature and cooking time on Warner- Bratzler tenderness measurement and collagen content in rabbit meat. Meat Science, v. 66, n. 1, p. 91-96, 2003.

4. DELGADO, E. F. et al. Brazilian consumers'perception of tenderness of beef steaks classified by shear force and a taste. Scientia Agrícola, v. 63, n. 3, p. 232-239, 2006.

5. JOHNSON, D. D. et al. Effects of percentage Brahman in Angus breading age-season of feading and slaugther end point on meat palatability and muscle characteristics. Journal of Animal Science, v. 68, n. 7, p. 1980-1986, 1990.

6. KOOHMARIE, M. The biological basis of meat tenderness and potential genetic approaches for its control and prediction. In: $48^{\text {th }}$ RECIPROCAL MEAT CONFERENCE, Santo Antonio.
Proceedings..., Santo Antonio, Texas, EUA: AMSA, p. 69-75, 1995.

7. NEELY, T. R. et al. Beef consumer satisfaction:role of cut, USDA quality grade, and city on in-home consumer ratings. Journal of Animal Science, v. 76, n. 4, p. 1027-1032, 1998.

8. OFFER, G. Progress in the biochemistry, physiology and structure of meat. In: EUROPEAN MEETING OF MEAT RESEARCH WORKERS, $30^{\text {th }}$ Bristol, 1984. Proceedings... Bristol, Inglaterra: p. 217-234, 1984.

9. ORMENESE, F. M. Efeito do processo Tender Tainer de maturação sob pressão na maciez da carne bovina. Tese (Doutorado em Tecnologia de Alimentos) - Universidade Estadual de Campinas. Campinas. 93 p. 1995.

10. PALKA, K. Changes in intramuscular connective tissue and collagen solubility of bovine $\mathrm{m}$. Semitendinosus during retorting. Meat Science, v. 53, n. 3, p. 189-194, 1999.

11. PALKA. K. The influence of post-mortem ageing and roasting on the microstructure, texture and collagen solubility of bovine Semitendinosus muscle. Meat Science, v. 64, n. 1, p. 191-198, 2003

12. PLANT, T. M.; TAYLOR, D. G.; DHANDA, J. S. Tenderness relationships between four raw and cooked beef muscles. In: INTERNATIONAL CONGRESS MEAT SCIENCE AND TECHNOLOGY, $43^{\circ}$. Auckland. 1997. Proceedings..., Auckland: MIRINZ. p. 594-595, 1997.

13. RESURRECCION, A. V. A. Sensory aspects of consumer choices for meat and meat products. Meat Science, v. 66, n. 1, p. 11-20, 2003.

14. ROWE, R. W. D. Electron microscopy of bovine muscles. II The effects of heat denaturation on post rigor sarcolemma and endomysium. Meat Science, v. 26, n. 4, p. 281-294, 1989.

15. RYBKA, S. et al. Storage characteristics of extended shelf-life cook-chill meals. Food Australia, v. 5, n. 53, p. 191-195, 2001.

16. SAVELL, J. M.; SMITH, G. C. Chapter Anatomy. In: SAVELL, J. M.; SMITH, G. C. Meat science laboratory manual. College Station: Texas A \& M University, 48 p., 1999

17. SHACKELFORD, S. D.; WHEELER, T. L.; KOOHMARIE, M. Relationship between shear force and trained sensory painel tenderness rating of 10 major muscles from Bos indicus and Bos taurus cattle. Journal of Animal Science, v. 73, n. 11, p. 3333-3340, 1995.

18. SPECIAL PROGRAM FOR SOCIAL SCIENCE (SPSS). Guide to data analysis (Software) Chicago USA SPSS Inc., 1986.

19. STUMBO, C. R. Thermobacteriology in food processing. $1^{a}$ edição, London, Blackie Academic Press, 236 p., 1965.

20. TATUM, J. D.; SMITH, G. C.; BELK, K. E. New approaches for improving tenderness, quality, and consistency of beef. In: AMERICAN SOCIETY OF ANIMAL SCIENCE California, 2000. Proceedings..., California:American Society of Animal Science, p. 1-10, 2000.

21. TORNBERG, E. Effects of heat on meat proteins - Implications on structure and quality of meat products. Meat Science, v. 70, n. 3, p. 493-508, 2005.

22. VAUDAGNA, S. R. et al. Sous vide cooked beef muscles: effects of low temperature-long time (LT-LT) treatments on their quality characteristics and storage stability. International Journal of Food Science and Technology, v. 37, n. 4, p. 425-441, 2002.

23. WHEELER, T. L.; CUNDIF, L. V.; KOCH, R. M. Effect of marbling degree on beef palatability in Bos taurus and Bos indicus cattle. Journal of Animal Science, v. 72, n. 12, p. 3145-3151, 1994. 